\title{
Phytochemical Screening and Antimicrobial Studies in Leaf Extracts of Indigofera aspalathoides (Vahl.)
}

\author{
Tamilarasan Tamil Kumar ${ }^{1}$, Seeni Mohamed Salique ${ }^{1}$, Mohamed Hussain Muhammad Ilyas ${ }^{1}$, Nooruddin Thajud- \\ din $^{2}$, Annamalai Panneerselvam³ ${ }^{3}$ Mohamed Khan Syed Ali Padusha ${ }^{4}$, Hussain Syed Jahangir ${ }^{*}$
}

\section{Tamilarasan Tamil Kumar', Seeni Mohamed Salique ${ }^{1}$, Mohamed Hussain Mu- hammad Ilyas ${ }^{1}$, Nooruddin Thajuddin ${ }^{2}$, Annamalai Panneerselvam ${ }^{3}$, Mo- hamed Khan Syed Ali Padusha ${ }^{4}$, Hussain Syed Jahangir ${ }^{1, *}$}

'Post Graduate and Research Department of Botany, Jamal Mohamed College

(Autonomous), Tiruchirappalli-620020,

Tamil Nadu, INDIA.

${ }^{2}$ Department of Microbiology, School of Life Sciences, Bharathidasan University, Tiruchirappalli-620024, Tamil Nadu, INDIA. ${ }^{3}$ Post Graduate and Research Department of Botany and Microbiology, A. Veeriya Vandayar Memorial Sri Pushpam College (Autonomous), Poondi-613503, Thanjavur District, Tamil Nadu, INDIA.

${ }^{4}$ Post Graduate and Research Department of Chemistry, Jamal Mohamed College (Autonomous), Tiruchirappalli-620020, Tamil Nadu, INDIA.

\section{Correspondence}

Dr. H. Syed Jahangir, M.Sc., M.Phil., Ph.D.

Associate Professor, Post Graduate and Research Department of Botany, Jamal Mohamed College (Autonomous), Tiruchirappalli-620020, Tamil Nadu, INDIA.

Phone no : (+91) 9443817623

E-mail: syedbot2000@gmail.com

History

- Submission Date: 10-03-2018.

- Review completed: 28-06-2018

- Accepted Date: 23-07-2018

DOI : 10.5530/pj.2018.6.207

Article Available online

http://www.phcogj.com/v10/i6

Copyright

(C) 2018 Phcog.Net. This is an openaccess article distributed under the terms of the Creative Commons Attribution 4.0 International license.

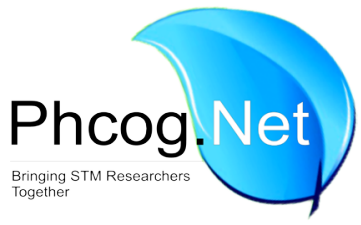

\begin{abstract}
Introduction: In traditional Indian herbal medicine, the plant Indigofera aspalathoides (Vahl.) has been used to treat various human ailments. Methods and Results: Various phytochemical compounds (Rf value) such as Tannin (1.14), Flavonoid (1.14), Saponin (0.87), Sterol (0.88) and Phenol (0.86) were found in the leaf extract. The antimicrobial effects of the phytoconstituents were examined for three bacterial and fungal species. The highest anti-bacterial and antifungal activities were found in flavonoid compound, where the maximum zone of inhibition was recorded in Staphylococcus aureus $18 \mathrm{~mm}$ compared to positive control chloramphenicol $(24 \mathrm{~mm}) .13 \mathrm{~mm}$ observed in A. flavus and A. ochraceous where positive control streptomycin exhibits $18 \mathrm{~mm}$. GC-MS analysis revealed the presence of three major compounds in $8 \alpha$

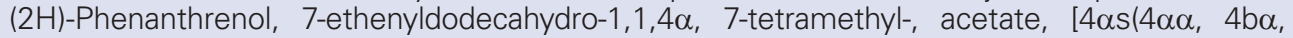
$7 \alpha, 8 \alpha \alpha, 10 \alpha \alpha)]$, Benzoic acid, 4-methyl- , 2-oxo-2- phenylethyl ester and Cyclohexanol, 5-methyl-2-(1-methylethyl)-, [1S- $(1 \alpha, 2 \alpha, 5 \alpha)]$ in the crude extracts. The preparative HPLC analysis proved the presence of single peak from the crude flavonoid compounds, where the absorption maximum was between 207-290nm exhibited by the UV spectrum analysis. FTIR spectrum confirmed the presence of amide group, phenol group, carboxylic acid, alkynyl, alkene and aromatic ring. NMR studies proved the presence of phenyl group, methyl group and $\mathrm{H}_{2} \mathrm{C}-\mathrm{CH}$ group and their molecular weight recorded as 353 through the mass spectrum analysis. Conclusion: The identified compound considered as the vital compound to design the "green antimicrobial drugs".
\end{abstract}

Key words: Indigofera aspalathoides, Antimicrobial activities, HPLC, GC-MS, NMR, MS.

\section{INTRODUCTION}

Plants have been an important source of medicine for thousands of years. Various plant parts like leaves, flowers, fruits, stem and root have their own bioactive compounds used to treat many diseases dated back to prehistory and people of all continents have this old tradition. ${ }^{1-2}$ Today, scientists and the general public recognize their value as a source of new or alternative medicinal products. Recently, wide array of research highlight the potential health beneficial principles from phytal sources. Herbal medicine is based on the natural plant products and that can promote health and alleviate illness. Modern drugs or conventional medicines are often viewed as impersonal, emphasizing crisis intervention. The World Health Organization (WHO) also considers phytotherapy in its health programs and suggests basic procedures for validation of drugs from plant origin ${ }^{3}$ and estimates that up to $80 \%$ of people still rely mainly on traditional remedies such as herbs for their medicine. ${ }^{4}$ Approximately $25-50 \%$ of current pharmaceuticals are derived from plants, the surge to produce 'Green Medicine' from natural sources are gradually increased.
Herbal drugs play an important role in health care programmes in developing countries like India ${ }^{5}$ and often been referred to as the Medicinal Garden of the world. The clinical use of plants described in Indian Vedas for curing different diseases. At this stage, India has a unique position in the world where a number of recognized Traditional systems of medicine i.e. Ayurveda, Siddha, Unani, Homeopathy, Yoga and Naturopathy ${ }^{6}$ exists. Indigenous plants are reservoirs of various metabolites and provide unlimited source of important chemicals that have diverse biological properties. ${ }^{7}$ Plant and its derivatives have long history to clinical relevance as a source of potential general chemotherapeutic agents. ${ }^{8}$

Phytochemical tests are considered as the one of the standard pharmacognostical parameter. ${ }^{9}$ Phytochemicals are actually organic compounds which possess medicinal properties. ${ }^{10}$ The steadily increasing microbial resistance to existing drugs was a serious problem in antimicrobial therapy and necessitates continuing research into new classes of antimicrobials. ${ }^{11-12}$ One way to prevent antibiotic

Cite this article: Kumar TT, Salique SM, Ilyas MHM, Thajuddin N, Panneerselvam A, Padusha MSA, Jahangir HS. Phytochemical Screening and Antimicrobial Studies in Leaf Extracts of Indigofera aspalathoides (Vahl.). Pharmacog J. 2018;10(6):1208-15. 
resistance of pathogenic species was to use new compounds that were not based on existing synthetic antimicrobial agents. ${ }^{13-14}$ GC-MS is performed to identify the compounds in the ethanol extracts of the plant, and their compounds ${ }^{15}$ determined by NIST data library. Many studies have been undertaken with the aim of determining the antimicrobial and phytochemical constituents of medicinal plants and using them for the treatment of both topical and systemic microbial infections as possible alternatives to chemical synthetic drugs to which many infectious microorganisms have become resistant. ${ }^{16-17}$

Indigofera aspalathoides (Vahl.) belongs to the family Fabaceae and it grows abundantly in Southern India. This plant has been used in traditional Indian medicine for the treatment of oedematous tumors, gastric hyperacidity, ulcers, toothache and abscesses. The stem was traditionally used for various skin disorders and cancer. ${ }^{18}$ The present study was aimed to investigate the phytochemical constituents of I. aspalathoides and its antimicrobial studies against the selected different pathogenic microorganisms.

\section{MATERIALS AND METHODS}

\section{Plant collection and Crude extraction}

Indigofera aspalathoides plants were collected from the fields located in Tamil University campus, Thanjavur (Tamil nadu, India) and authenticated at Department of Botany, Rapinat Herbarium, St. Joseph's college (Autonomous), Tiruchirappalli (Tamil Nadu, India). All the solvents and chemicals used obtained from MERCK India (AR grade). The leaves were washed under running tap water and rinsed with $0.1 \% \mathrm{HgCl}_{2}$ and then with sterilized distilled water. Surface sterilized leaves were shade dried for $48 \mathrm{~h}$ and powdered. Plant powder (1gm) was thoroughly mixed with ethanol $(10 \mathrm{ml})$ and kept at $32 \pm 2^{\circ} \mathrm{C}$ for $24 \mathrm{~h}$ and filtered by using muslin cloth. The filtrate was centrifuged at $5000 \mathrm{rpm}$ for 10min (REMI, Elektrotechnik Limited, VASI, INDIA) and the supernatant filtered by Whatman filter No.1 under strict aseptic conditions.

\section{Phytochemical screening}

The ethanolic leaf extracts of $I$. aspalathoides were qualitatively tested for the presence of phytochemical constituents according to Vogel's technique. ${ }^{19}$ The secondary metabolites such as Saponin and sterols, ${ }^{20}$ phenols, ${ }^{21}$ flavonoids ${ }^{22}$ and tannins ${ }^{23}$ were quantitatively analysed by using thin layer chromatographic methods.

\section{Test Microorganisms}

Two Gram negative (Escherichia coli and Salmonella typhi), one Gram positive bacteria (Staphylococcus aureus) and three fungal strains (Aspergillus niger, Aspergillus flavus and Aspergillus ochraceous) procured from Microbial Germ Plasm Culture Collection Unit (Sri Gowri Biotech Research Academy, Thanjavur) and maintained in the laboratory by periodic subculture. The bacteria were maintained on Nutrient agar medium and fungi were maintained on Potato Dextrose agar (PDA) medium. A loopful of bacterial (12 hrs grown) and fungal ( $36 \mathrm{~h}$ grown) culture were sub cultured on Muller Hinton Agar (MHA) and PDA respectively. Colonies of the pure organism were cultured in $10 \mathrm{ml}$ broth medium and incubated at $37^{\circ} \mathrm{C}$ overnight. Cultures were adjusted to suspension density equal to $0.5 \mathrm{Mc}$ Farland turbidity standards ${ }^{24}$ which has an approximate cell density of $1.5 \times 10^{6} \mathrm{Cfu} / \mathrm{ml}^{25}$

\section{Determination of Antimicrobial Activity}

Sensitivity test for bacterial and fungal strains to ethanolic leaves extract of $I$. aspalathoides was measured by means of zone of inhibition using well diffusion assay. MHA and PDA medium were used for bacterial and fungal species growth. A sterile swab was dipped in broth suspension of $0.5 \mathrm{ml}$ MacFarland as standard. The entire surface of the medium was spread uniformly by their respective samples and the wells were made by sterile well borer and filled with $200 \mu \mathrm{l}$ of secondary metabolites isolated through TLC method. The inoculated plates were incubated for $24 \mathrm{~h}$ at $37^{\circ} \mathrm{C}$ for bacteria and $72 \mathrm{hrs}$ at $28^{\circ} \mathrm{C}$ for fungus to find their antibacterial and antifungal efficacy. ${ }^{26}$ Pure solvent used as negative control and $200 \mu \mathrm{l}$ of a broad spectrum antibiotic chloramphenicol (for bacteria) and streptomycin (for fungi) as standard positive control. Each test was performed in triplicates.

\section{Characterization of the compound}

The potent secondary metabolite which showed highest antimicrobial effect against bacterial and fungal strains was further subjected for characterization studies.

\section{Gas Chromatograph-Mass Spectrophotometer (GC-MS) and High Performance Liquid Chromatography (HPLC)}

The GC-MS analysis of ethanolic leaf extracts were carried out using a GC Clarus 500 Perkin Elmer (Shelton, USA), equipped and coupled to a mass detector Turbo mass gold - Perkin Elmer Turbomass $5.1 \mathrm{spec}$ trometer with an Elite-1 (100\% Dimethyl poly siloxane). Using computer searches on a NIST Ver.2.1 MS data library and comparing the spectrum obtained through GC-MS compounds present were identified. ${ }^{27}$

The crude compounds isolated from extract were first subjected for analytical HPLC analysis. The compound which showed highest peak was isolated through preparative HPLC analysis with LC-20AT prominence liquid chromatograph pump and SPD-20A prominence UV-Vis detector and Rheodyne type injector (Shimadzu Corporation, Japan). ${ }^{28}$

\section{UV-Visible spectrophotometer and Fourier Transform Infrared} Spectroscopy (FTIR)

The spectrum of a single eluted compound with highest peak value from preparative HPLC was further recorded between 190 to $600 \mathrm{~nm}$ on a UV-Visible spectrophotometer coupled with DAD detector (Agilent Technologies, Cork, Ireland). The pure compound was grinded and dispersed with 95mg of micronized dried IR grade Potassium bromide $(\mathrm{KBr})$. Pellets of samples were prepared using hydraulic press as a salt disc into $1 \mathrm{~mm}$ pellet and scanned over a wave number range of $4000 \mathrm{~cm}^{-1}$ to $400 \mathrm{~cm}^{-1}$ using IR Affinity-1 Perkin Elmer 2000 model FTIR spectrometer (Thermo Fisher Scientific Inc., MA, and USA). The wave numbers of different components present in bioactive sample were analyzed using IR solution software and the possible stretches of functional groups were identified. ${ }^{28}$

\section{Nuclear Magnetic Resonance (NMR) and Mass Spectroscopy (MS) study}

${ }^{1} \mathrm{H}$ NMR spectra of the isolated compound was recorded on a NMR spectrometer (Make: Bruker Biospin, Switzerland, Model $300 \mathrm{MHz}$ AVANCE II) equipped with a $5 \mathrm{~mm}$ BBO probe. The experiments were recorded at $298.15 \mathrm{~K}$ using the standard pulse sequence library of Top Spin 1.3 followed by processing of the data by using Top Spin 3.2 software. The result graph was compared with the reference chart and possible functional groups present were determined. ${ }^{29}$

The mass spectrum of the bioactive compounds was recorded on JEOL GC MATE II (USA). The instrument was fitted with HP 5MS capillary column of medium polarity. Helium was used as a carrier gas at a flow rate of $1 \mathrm{~mL} / \mathrm{min}$. The sample $(1 \mu \mathrm{L})$ was injected at the flow rate of $4 \mathrm{~mL} / \mathrm{min}$ and the purge flow rate was $3 \mathrm{~mL} / \mathrm{min}$. The injector and interface temperatures were maintained at $220^{\circ} \mathrm{C}$.

\section{RESULTS}

\section{Phytochemical screening}

Ethanolic leaves extract of I. aspalathoides were examined for the presence of phytoconstituents. The results (Table 1) revealed that flavonoids, tannin, phenol, saponin and sterol presence in the ethanolic leaves 
Table 1: Qualitative Phytochemical Screening and analysis of Indigofera aspalathoides by TLC.

\begin{tabular}{|c|c|c|c|c|c|}
\hline $\begin{array}{l}\text { S. } \\
\text { No }\end{array}$ & $\begin{array}{l}\text { Compound } \\
\text { Tested }\end{array}$ & $\begin{array}{c}\text { Test Applied } \\
\text { /Reagent } \\
\text { Used }\end{array}$ & Observation & Result & $\begin{array}{c}\text { Rf } \\
\text { Value }\end{array}$ \\
\hline 01. & Tannin & Spot test & $\begin{array}{c}\text { Dark green color } \\
\text { spot }\end{array}$ & + & 1.14 \\
\hline 02. & Flavonoid & Spot test & Yellow color spot & + & 1.14 \\
\hline 03. & Saponin & $\begin{array}{l}\text { Iodine } \\
\text { vapours }\end{array}$ & Yellow color spot & + & 0.87 \\
\hline 04 & Sterol & $\begin{array}{l}\text { Folin- } \\
\text { ciocalteu's } \\
\text { reagent }\end{array}$ & Black color spot & + & 0.88 \\
\hline 05. & Phenol & $\begin{array}{l}\text { Folin- } \\
\text { ciocalteu's } \\
\text { reagent }\end{array}$ & Blue color spot & + & 0.86 \\
\hline
\end{tabular}

+ : Presence

Table 2: Antibacterial activity of phytocompounds in I. aspalathoides (Vahl.)

\begin{tabular}{ccccccc}
\hline \multirow{2}{*}{$\begin{array}{c}\text { S. } \\
\text { No. }\end{array}$} & $\begin{array}{c}\text { Bacterial } \\
\text { Cultures }\end{array}$ & \multicolumn{5}{c}{$\begin{array}{c}\text { Phytocompounds Test } \\
\text { (Zone of inhibition mm) }\end{array}$} \\
\cline { 3 - 7 } & & Flavonoid & Tannin & Sterol & Phenol & Saponin \\
\hline 1. & Escherichia coli & 15 & 15 & 10 & 10 & 7 \\
2. & Salmonella typhi & 16 & 18 & 10 & 5 & 10 \\
3. & $\begin{array}{c}\text { Staphylococcus } \\
\text { aureus }\end{array}$ & 18 & 15 & 10 & - & 5 \\
\hline
\end{tabular}

Positive control: Chloramphenicol for E. coli-22mm; S. typhi-20mm; Staph. aureus - $24 \mathrm{~mm}$.

Negative control: Ethanol - 0mm

extract of $I$. aspalathoides. The identified phytoconstituents were spot identified from TLC and observed under day light condition and they appeared to be in different colors with different $\mathrm{Rf}$ values ranging from 0.86 to 1.14 .

\section{Antimicrobial assay}

The phytoconstituents in the ethanolic leaves extract of $I$. aspalathoides exhibited varied activity against the tested bacteria and fungi. $200 \mu$ of Chloramphenicol was used as positive control whereas the inhibition zones were found as $22 \mathrm{~mm}, 20 \mathrm{~mm}$ and $24 \mathrm{~mm}$ for E. coli, S. typhi and Staph. aureus respectively. Among the phytochemical compounds, the highest bacterial inhibition zone was observed against Staph. aureus $(18 \mathrm{~mm})$, followed by $S$. typhi $(16 \mathrm{~mm})$, and least inhibition zone was noted in E. coli $(15 \mathrm{~mm})$ on flavonoid treatment. Tannin results showed with highest inhibition observed against $S$. typhi $(18 \mathrm{~mm})$, followed by Staph. aureus and E. coli $(15 \mathrm{~mm}) .10 \mathrm{~mm}$ of zone of inhibition was observed in S. typhi, Staph. aureus and E. coli on treated with sterol, phenol results showed with highest inhibition against E. coli $(10 \mathrm{~mm})$, followed by $S$. typhi $(5 \mathrm{~mm})$ and no results was found in Staph. aureus. Saponin result shows highest zone of inhibition against S. typhi $(10 \mathrm{~mm})$, followed by E. coli $(7 \mathrm{~mm})$ and Staph. aureus ( $5 \mathrm{~mm}$ ) (Table 2 and Figure 1). Streptomycin $(200 \mu \mathrm{l})$ was used as positive control which showed $18 \mathrm{~mm}$ inhibition zone against the three fungal species. Flavonoids from I. aspalathoides possess antifungal activity with the highest diameter zone of inhibition against Aspergillus flavus and Aspergiilus ocharaceous $(13 \mathrm{~mm})$, and least inhibition zone was observed in Aspergillus niger

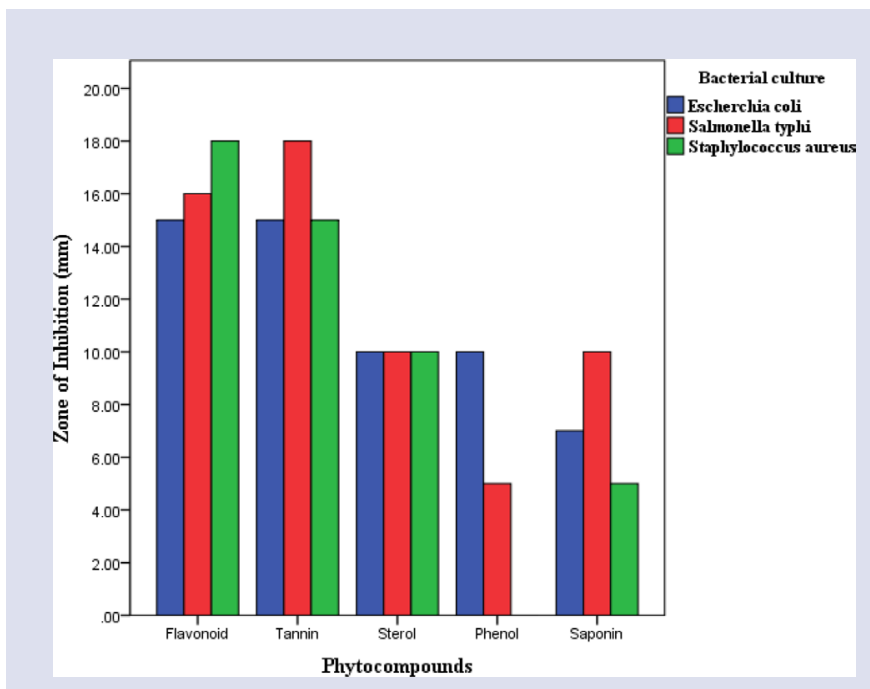

Figure 1: Antibacterial effect of secondary metabolites isolated from I. aspalathoides.

Table 3: Antifungal activity of phytocompounds in I. aspalathoides (Vahl.)

\begin{tabular}{ccccccc}
\hline S.No. & Fungal Cultures & \multicolumn{5}{c}{$\begin{array}{c}\text { Phytocompounds Test } \\
\text { (Zone of inhibition mm) }\end{array}$} \\
\cline { 3 - 7 } & & Flavonoid & Tannin & Sterol & Phenol & Saponin \\
\hline 1. & Aspergillus niger & 12 & 10 & 9 & 13 & 12 \\
2. & Aspergillus flavus & 13 & 12 & 13 & 12 & 13 \\
3. & $\begin{array}{c}\text { Aspergillus } \\
\text { ochraceous }\end{array}$ & 13 & 12 & 7 & 10 & 12 \\
\hline
\end{tabular}

Positive control: Streptomycin - 18mm; Negative control: Ethanol - 0mm

(12mm). Tannin results showed highest inhibition against $A$. flavus and A. ochraceous $(12 \mathrm{~mm})$ and least inhibition zone in $A$. niger $(10 \mathrm{~mm})$. Sterol results showed with highest inhibition in A. flavus $(13 \mathrm{~mm})$, followed by A. niger ( $9 \mathrm{~mm}$ ) and least inhibition zone in A. ocharaceous $(7 \mathrm{~mm})$. Phenol results showed highest inhibition zone in A. niger $(13 \mathrm{~mm})$, followed by A. flavus $(12 \mathrm{~mm})$ and least inhibition zone in A. ocharaceous $(10 \mathrm{~mm})$. Saponin results showed highest inhibition against $A$. flavus (13mm), followed by least inhibition zone in $A$. ocharaceous and $A$. niger (12mm) (Table 3 and Figure 2). Flavonoid was found to be more potential against bacterial and fungal pathogens. So, therefore flavonoids from I. aspalathoides were further elucidated for characterization studies.

\section{GC-MS}

The crude ethanolic leaves extract of $I$. aspalathoides was analyzed by GC-MS. A total of 11 different organic compounds were identified and their constituents (Table 4 and Figure 3) were as follows: 3-Methyl2-(2-oxopropyl)furan (2.50\%), Cyclobutanone, 2,2,3-trimethyl-(3.33\%), 2,4,6,8-Tetramethyl-1-undecene (0.83\%), a-Cubebene (2.92\%), (Z,Z)- $\alpha$ Farnesene (5.00\%), 2-Pyridinemethanamine-N-methyl-(0.42\%), (+)-Epibicyclosesquiphellandrene (5.42\%), Hydrazine, 1,2-dimethyl-(0.42\%), Cyclohexanol, 5-methyl-2-(1-methylethyl)-, [1S-(1a,2a,5a)]- (6.67\%), $8 a$ (2H)-Phenanthrenol, 7-ethenyldodecahydro-1,1,4a, 7-tetramethyl-,

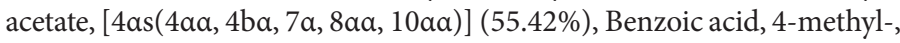
2-oxo-2- phenylethyl ester (17.08\%) respectively. 


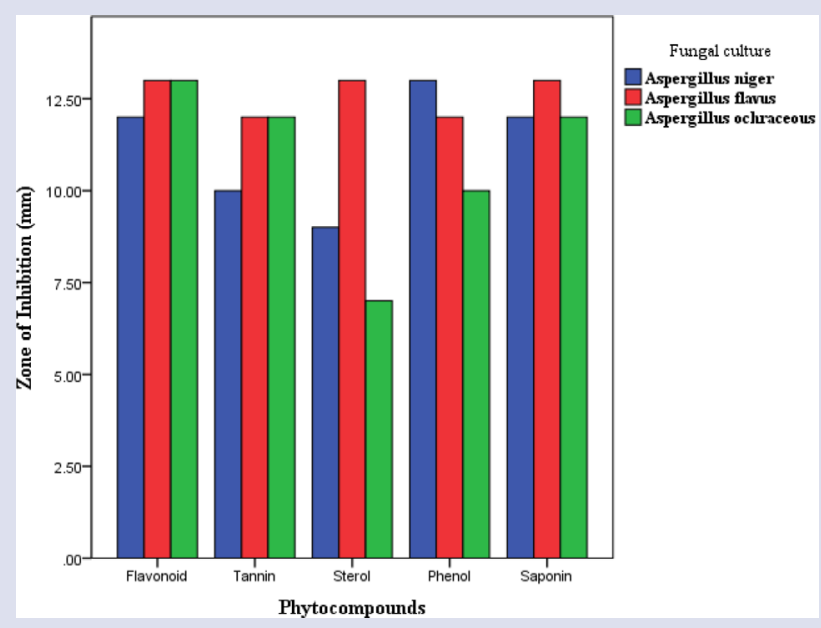

Figure 2: Antifungal effect of secondary metabolites isolated from I. aspalathoides.

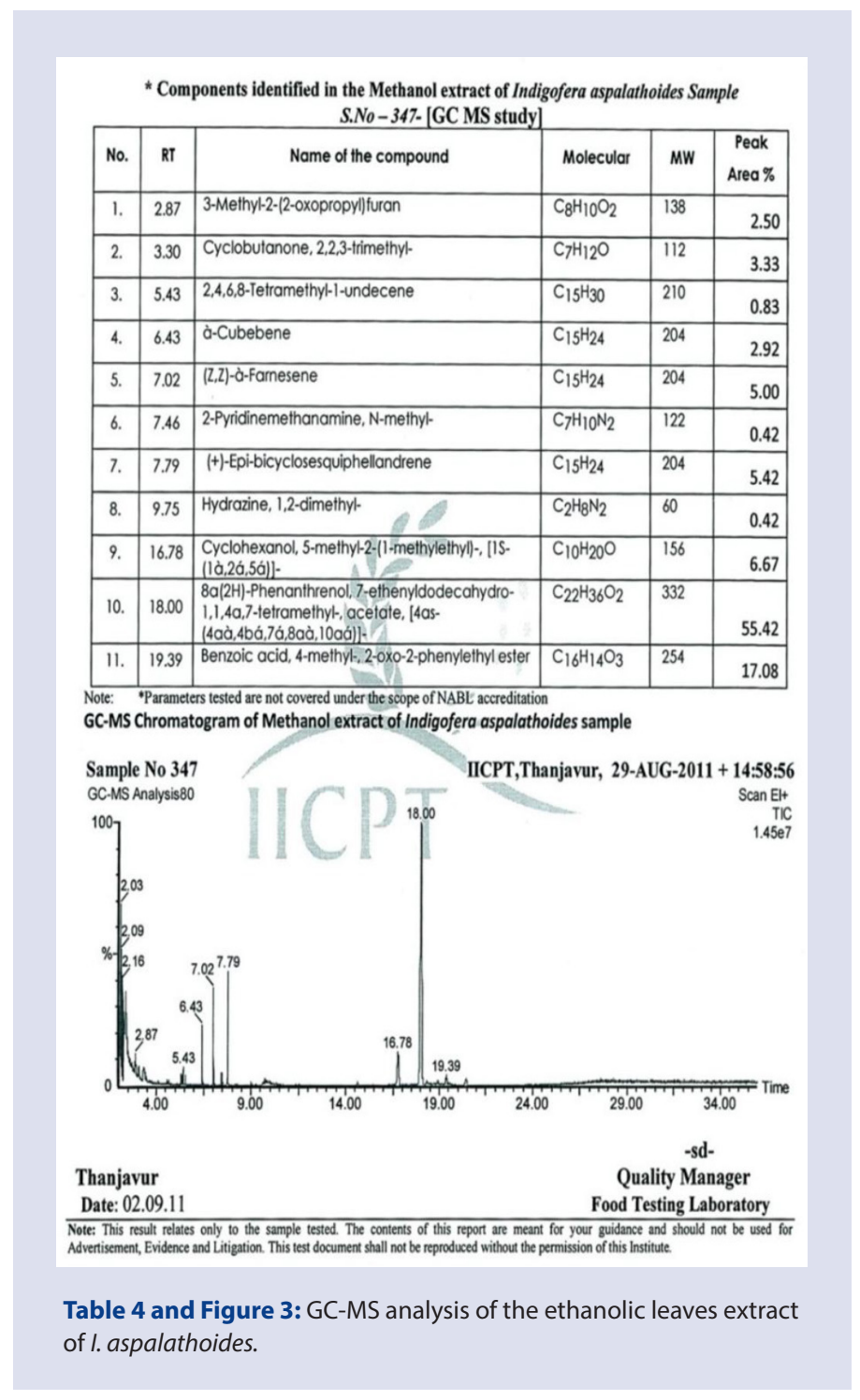

HPLC

Analytical HPLC chromatogram revealed the presence of five different peaks of the crude flavonoids (Figure 4). The highest peak (62.51\%) was chosen for the present study. Through preparative HPLC analysis, a single compound was eluted at the retention time of 5.002 with the peak area and height of $100 \%$ is designated as 'A' compound (Figure 5). The eluted compound was further subjected to partial structural elucidation through UV, FTIR, NMR and MS studies.

UV

The UV-visible spectroscopic profile of eluted compound (Figure 6) of the plant extract was studied at a wavelength range of 190 to $1100 \mathrm{~nm}$. Three major bands were recorded at wavelength range of $207 \mathrm{~nm}, 223$ $\mathrm{nm}$ and $271 \mathrm{~nm}$ with absorbance value of $2.1,2.4$ and 1.7 respectively.

FTIR

The FTIR spectrum was performed to identify the presence of functional groups in the purified compound 'A' of I. aspalathoides based on the peak values in the infrared region. The major bands were observed at 3944.39, 3832.76, 3415.38, 2963.75, 2649.50, 2544.83, 2388.65, 2060.32, $1640.07,1372.78,1033.79$ and $666.69 \mathrm{~cm}^{-1}$. The peaks at 3944.39 and $3832.76 \mathrm{~cm}^{-1}$ were attributed to amide N-H stretch. $3415.38 \mathrm{~cm}^{-1}$ corresponds to phenol O-H stretch. The peak at 2963.75, 2649.50, $2544.83 \mathrm{~cm}^{-1}$ represents carboxylic acid O-H stretch. 2388.65, 2060.32 $\mathrm{cm}^{-1}$ attributes to alkynyl $\mathrm{C} \equiv \mathrm{C}$. $1640.07 \mathrm{~cm}^{-1}$ corresponds to $\mathrm{C}=\mathrm{C}$ stretch and $1372 \mathrm{~cm}^{-1}$ corresponds to $\mathrm{C}-\mathrm{H}$ bending. $1033.79 \mathrm{~cm}^{-1}$ attributed to $\mathrm{C}-\mathrm{F}$ stretch and $666.69 \mathrm{~cm}^{-1}$ represents C-H bending (Figure 7).

\section{$N M R$}

The eluted 'A' compound through NMR analysis revealed the presence of multiplets at 57.6-7.8 ppm that indicated the presence of phenyl group. Multiplets found in the region of 1.2-1.8 ppm showed the presence of methylene group. Presence of triplet and a doublet at $3.9-4.23 \mathrm{ppm}$ confirmed the presence of $\mathrm{H}_{2} \mathrm{C}-\mathrm{CH}$ group (Figure 8).

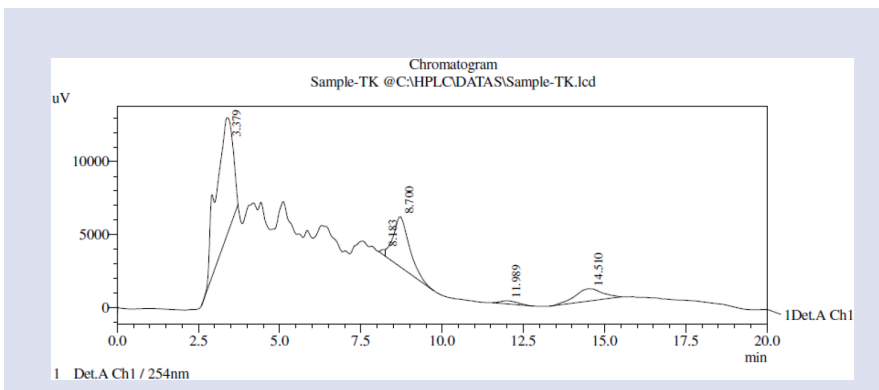

Figure 4: Analytical HPLC analysis of $I$. aspalathoides.

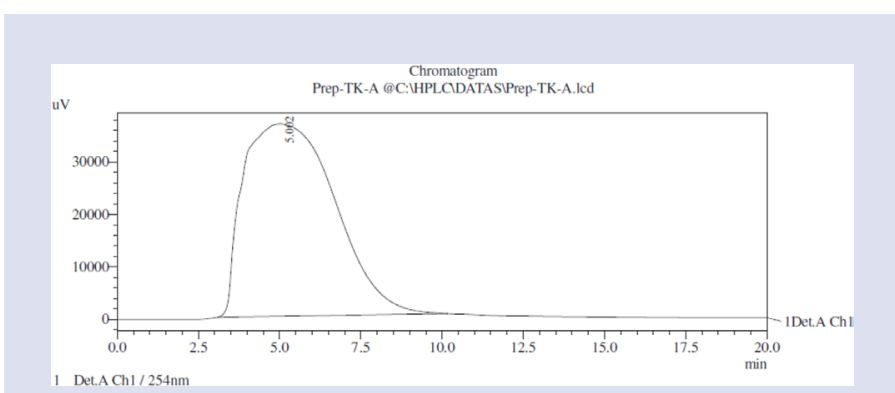

Figure 5: Preparative HPLC analysis of I. aspalathoides 


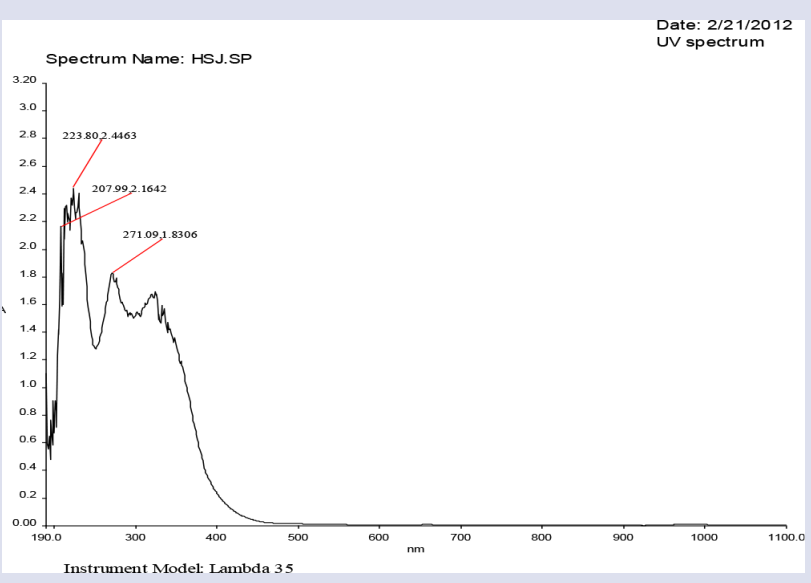

Figure 6: UV spectroscopic profile of the isolated compound 'A'.

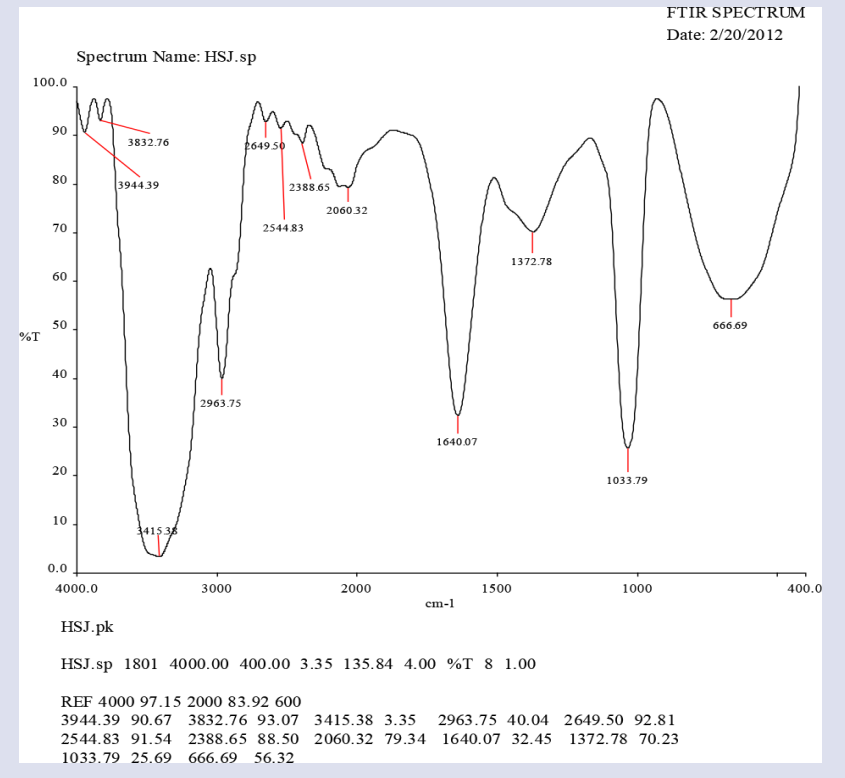

Figure 7: FTIR spectroscopic profile of the isolated compound 'A'.

\section{MS study}

A Peak observed at m/e 353 is assigned to molecular ion peak and hence the molecular weight of the fragment is 353 . A highest peak appearing at $\mathrm{m} / \mathrm{e} 137$ assigned to the base peak. This peak is corroborated the maximum amount of the fragment and whose molecular weight is 137. Others peaks were appeared at m/e 148 and 273 accounted for other major fragments (Figure 9).

\section{DISCUSSION}

Bioactive phytochemicals in plants are of different molecular make-up and they were differently soluble in solvents with different polarity hydrophilic and hydrophobic nature. Various compounds extracted from Elephantopus scuber powdered leaf and rhizome samples whereas the methanol solvent elute more compounds such as flavanoids, phenol, steroid, tannin, terpene, xanthoprotien, sugars from leaf extracts and phenol, saponin, steroid, terpene, sugars from rhizome extracts. ${ }^{30}$ In the present study

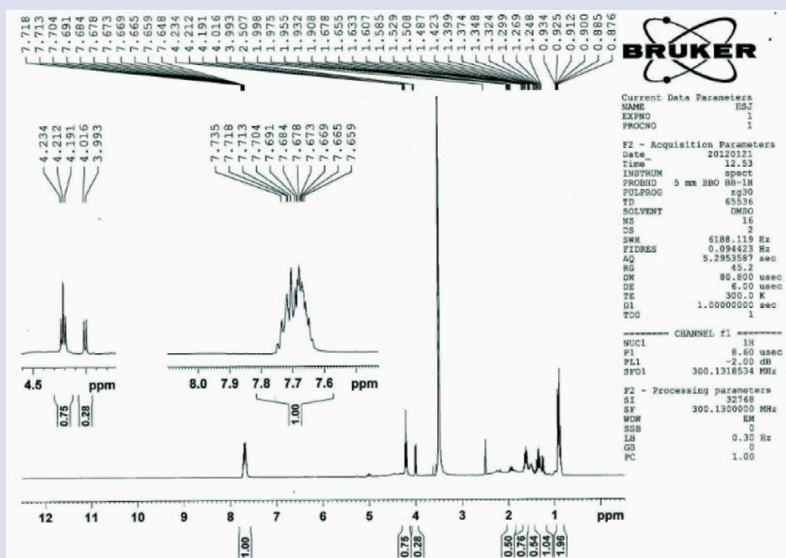

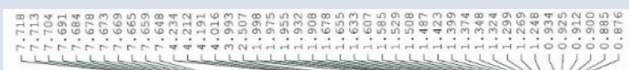
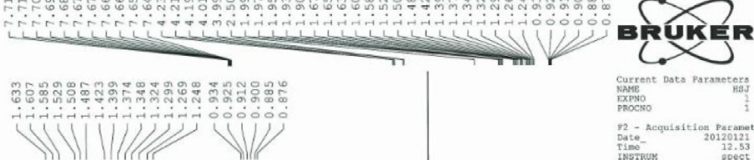

MVIVIII) vili
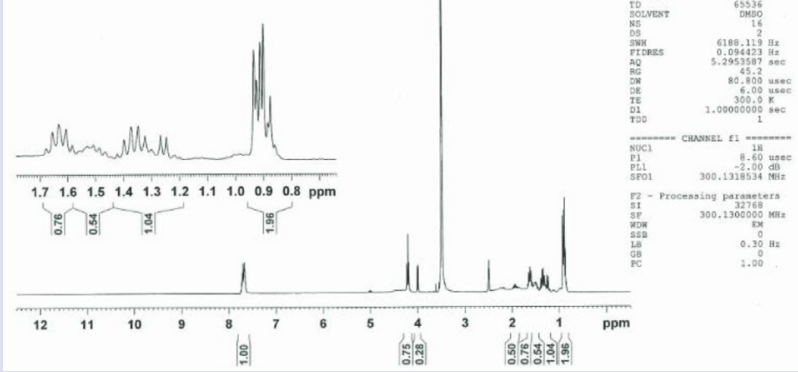

Figure 8: NMR spectroscopic profile of the isolated compound 'A'.

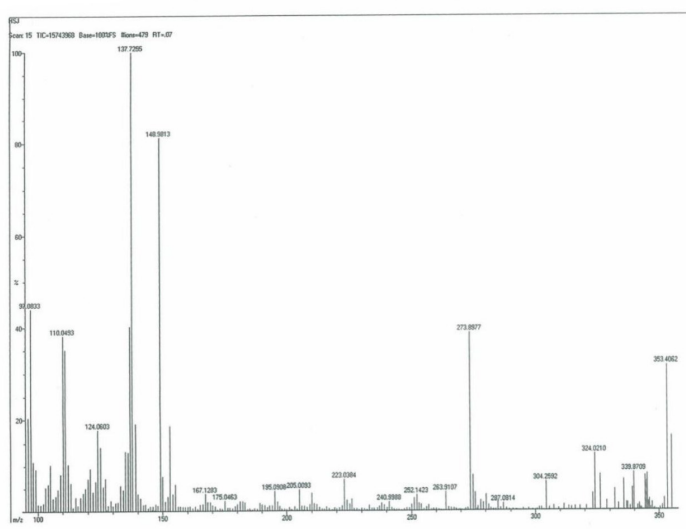

Figure 9: Mass spectrum study of the isolated compound ' $A$ '.

ethanol was used as a solvent source for the extraction of secondary metabolites in a dissolved state. Phytochemical studies were carried out on I. aspalathoides that indicated the presence of flavonoids, tannin, phenol, saponin and sterol. Flavonoids were hydroxylated phenolic substances which have been found in vitro and act as an effective antimicrobial substances ${ }^{31}$ against a wide array of microorganisms due to 
their ability to complex with extracellular and soluble proteins and bacterial cell walls. ${ }^{32}$ Phenolics and polyphenols were the largest groups of secondary metabolites which exhibit antimicrobial activity. ${ }^{33}$ The site(s) and number of phenol groups were thought to be related to their relative toxicity to microorganisms, with evidence that increased hydroxylation results in increased toxicity. ${ }^{34}$

The variation in the antibacterial activity of flavonoids was known to be related to their chemical structure, especially in regard to the number and positions of methoxy and phenolic groups within their structures. ${ }^{35-36}$ The antimicrobial effects of tannins have also been widely recognized. ${ }^{37}$ Saponins have been implicated as bioactive antibacterial agents of plants. ${ }^{38,-39}$ Plant steroids were known to be important for their cardiotonic activities, possess insecticidal and anti-microbial properties. In the present study the highest antibacterial activities observed in flavonoid content of I. aspalathoides against Staph. aureus (18mm), followed by S. typhi $(16 \mathrm{~mm})$ and E. coli $(15 \mathrm{~mm})$ followed by tannins, sterols and saponins. Similar results were also found against fungal pathogens.

However, the positive control such as chloramphenicol showed the highest zone of inhibition for bacteria such as $22 \mathrm{~mm}$ for E. coli, $20 \mathrm{~mm}$ for S. typhi and $24 \mathrm{~mm}$ for Staph. aureus. Similarly the streptomycin showed the highest zone of inhibition for A. niger $(18 \mathrm{~mm})$, A. flavus $(18 \mathrm{~mm})$ and A. ocharaceous (18mm). Even though, the pathogenic bacteria as well as fungi developed resistant activity against the selected pure compound Chloramphenicol and streptomycin. However, the $200 \mu \mathrm{l}$ of I. aspalathoides ethanolic leaf extracts prevents the resistance formation in the E. coli, S. typhi, and Staph. aureus and this may be due to the presence of flavonoids in the leaf extract. Further purification of the ethanolic leaf extracts may be useful to control the resistance formation and also prevent the pathogenesis.

A total of 11 different compounds were identified through GC-MS analysis of I. aspalathoides. Most of the major compounds from the extract were biologically active molecules. They were considered to be a part of plants defense systems, and as such have been included in a large group of protective molecules found in plants named "phytoanticipins" or "phytoprotectants" ${ }^{40-41}$ GC-MS analysis studies revealed the presence of twenty five compounds from the ethanolic leaf extracts of $C$. halicacabum where Cyclohexane-1, 4, 5-triol-3-one-1-carboxylic acid and 1-hydroxytetradecane represented as major compounds. ${ }^{42}$

3, 7, 11, 15-tetramethyl-2-hexadecen-1-o1, Squalene, 1-lodo-2-methylundecane, Vitamin E and Heptadecane, 2, 6, 10, 14-tetramethyl were also noted in the ethyl acetate extract of $H$. arnottiana. ${ }^{43} 1$, 2-benzenedicarboxylic acid, mono (2-ethylhexyl) ester and 9,12-tetradecadiene-1-olacetate and 3-chloro-N-(2-phenylethyl) propanamide were identified in stem bark of Mangifera indica (L.). ${ }^{44}$ Thus, the identification of a good number of compounds from I. aspalathoides by GC-MS might have some ecological significance.

The processing of a crude source material to provide a sample suitable for HPLC analysis as well as the solvent selection for sample reconstitution have a significant bearing on the overall success of natural product isolation. ${ }^{45}$ The results from HPLC crude extract profile for leaves of I. aspalathoides shows five peaks at the retention time between 0 to $20 \mathrm{mins}$ using methanol and water as solvent. Out of which the highest peak was only selected for further characterization. Similarly, Gallic acid, caffeic acid, rutin, quercetin and ferulic acid in the flavanoids from the methanolic leaf extracts of $I$. aspalathoides were observed. ${ }^{46}$

The result of this study shows that the UV-Vis spectrum scanning of flavonoid prepared with ethanol solvent produced absorbance spectra at wavelength range of $207 \mathrm{~nm}, 223 \mathrm{~nm}$ and $271 \mathrm{~nm}$. Peak locations or the peak wavelengths were specific for different bioactive compound groups and the peak height depends on the concentration of the compound. Flavonoids have an absorption maximum around 240-290nm, which was affected by the conjugation of ring structure and its substitution pattern. ${ }^{47}$ The spectra for phenolic compounds (tannins) typically lie in the range of $230-290 \mathrm{~nm}$. The result of UV-Vis spectroscopic analysis confirms the presence of tannins and flavonoids in the ethanolic extract of I. aspalathoides.

FTIR identifies and elucidates the chemical constituent ${ }^{48}$ which providing accurate measurements of whole range of biological specimens. ${ }^{49}$ The ethanolic extract of I. aspalathoides exhibited amide group, phenol group, carboxylic acid, alkynyl, alkene and aromatic rings. Identification of phenol and Flavonoid compounds in the ethanolic leaf extracts of Cardiospermum halicacabum ${ }^{42}$ which is similar to our results. Flavonoids and phenolic acids have the properties of antibacterial, antifungal, antiviral, hepatoprotective, immunomodulating, and anti-inflammatory. ${ }^{50}$ The presence of amino acids, alkenes, nitrates, nitrites, ethers, esters, aldehydes, alkynes, aromatic compounds, organic halogen compounds and carbohydrates in Ananus comosus peel by IR spectrum. ${ }^{51}$ Methanolic leaves extract of Clitoria ternatea exhibited the presence of phenols, alkanes, primary amines, aromatic amines, carboxylic acids, alkenes, primary and secondary amines. ${ }^{52}$

NMR spectroscopy provides the detailed structural information about organic compounds in the solution. ${ }^{53}$ NMR studies revealed that the presence of phenyl group, methyl group and $\mathrm{H}_{2} \mathrm{C}-\mathrm{CH}$ group in the leaf extracts of $I$. aspalathoides. But in methanol leaf extracts of E. agallocha exhibited the presence of alipathic alicyclic compounds, $\beta$-Substituted alipathic compounds and $\alpha$-Mono substituted alipathic compounds. ${ }^{54}$ This kind of analysis showed the presence of phenolic compounds and flavonoids, which can be isolated and further screened for different kinds of biologically active compounds and their activities depending upon the therapeutic uses.

\section{CONCLUSION}

It is hoped that this study would lead to the establishment of some biologically active molecules that could be used to formulate potential antimicrobial drugs of natural origin. Further studies will be needed to progress the I. aspalathoides ethanolic leaves extract on the same pathogens and as well as different obligate pathogens and also to focus on the isolated bioactive compound for its bio-efficacy and bioavailability in the arena of drug discovery.

\section{ACKNOWLEDGEMENT}

The authors are grateful to Dr. A.K. Khaja Nazeemudeen Sahib, Secretary and Correspondent and Dr. S. Ismail Mohideen, The Principal,, Jamal Mohamed College (Autonomous) for providing all the necessary facilities and encouragement. The authors thank IIT Madras for providing the Mass spectra facilities, IICPT for GC-MS, Sastra University (Thanjavur) for NMR and St. Joseph's College (Tiruchirappalli) for Plant authentication, UV, FTIR and HPLC analysis.

\section{CONFLICT OF INTEREST}

No conflict of interest.

\section{ABBREVIATIONS}

Rf: Retention factor; GC-MS: Gas chromatography mass spectroscopy; HPLC: High performance liquid chromatography; UV spec: Ultra violet spectroscopy; FTIR: Fourier transform infrared spectroscopy; MS: Mass spectroscopy; NMR: Nuclear magnetic resonance; nm: Nanometer; $\mathbf{H g C l}_{2}$ : Mercuric chloride; rpm: Rotation per minute; $\mathbf{C f u} / \mathbf{m l}$ : Colonies forming unit per milliliter; TLC: Thin layer chromatography; NIST: 
National institute of standards and technology; LC: Liquid chromatography; DAD: Diode array detector; IR: Infrared.

\section{REFERENCES}

1. Seyyed MS, Masumeh N, Ismaieel D, Hossein M. Antibacterial activity of hydroalcoholic extract of Callistemon citrinus and Albizia lebbeck. Amr J App Sci. 2010;7(1):13-6.

2. Prakash P, Madhumita S, Swetha S, Sai Krishna NMD. Comparative analysis of biochemical compounds of leaf, flower and fruit of Courouptia guianensis and synthesis of silver nanoparticles. Pharmacogn J. 2018;10(2):315-23.

3. Anushia C, Sampathkumar P, Ramkumar L. Antibacterial and antioxidant activities in Cassia auriculata. Global J Pharm. 2009;3(3):127-30.

4. Tripathi L, Tripathi NJ. Role of biotechnology in medicinal plants. Trop J Pharmac Res. 2003;2(2):243-53

5. Gurrapu S, Mamidala, E. In vitro antibacterial activity of alkaloids isolated from leaves of Eclipta alba against human pathogenic bacteria. Pharmacog J. 2017;9(4):573-7.

6. Kumar N, Wani ZA, Dhyani S. Ethnobotanical study of the plants used by the local people of Gulmarg and its allied areas, Jammu and Kashmir, India. Int J Cur Res Biosci Plant bio. 2015;2(9):16-23.

7. Lico C, Santi L, Twyman MR, Pezzotti M, Avesani L. The use of plants for the production of therapeutic human peptides. Plant Cell Rep. 2012;31(3):439-51.

8. Cushnie TP, Lamb AJ. Antimicrobial activities of flavonoids. Int J Antimicro Agents. 2005;26(5):343-56.

9. Ranjani S. A review on Phytochemical, pharmacological and pharmacognostical profile of Wrightia tinctoria: Adulterant of kurchi. Phcog Rev. 2014;8(15):36-44.

10. Khattak WU, Rehman U, Khan SA, Barkat U, Sami U, Saima. Pharmacognostic Evaluation and Analgesic Efficacy of Ethanolic extract of Euphobia dracunculoides L. Pharmacogn J. 2017;9(5):644-53

11. Essawi T, Srour M. Screening of some Palestinian medicinal plants for antibac terial activity. J Ethnopharmacol. 2000;70(3):343-9.

12. Woodford N. Novel agents for the treatment of resistant Gram-positive infections. Expert Opin Invest Drugs. 2003;12(2):117-37.

13. Shah PM. The need for new therapeutic agents: What is in the pipeline?. Clin Microbio Infec. 2005;11:36-42.

14. Chanda S, Kaneria M, Vaghasiya KY. Evaluation of antimicrobial potential of some Indian medicinal plants against some pathogenic microbes. Ind J Nat Products Res. 2011;2:225-8.

15. Kerem C, Ali Y, Ilgaz A, Ergin MA. Antimicrobial activity and chemical composition screening of Anacyclus pyrethrum root. Ind J Pharm Edu Res. 2017:1(3):S244-S248.

16. Chopra I. The increasing use of silver based products as microbial agents: A useful development or a concern. J Antimicro Chemother. 2007;59(4):587-90.

17. Kumar A, Bhatii $V$, Kumar A, Patil S, Bhatia $V$, Kumar A. Screening of various plant extracts for antifungal activity against Candida species. W J Sci Tech. 2011;1(10):43-7.

18. Anonymous. The Wealth of Indian Raw Materials and industrial Products, Raw Materials; Council of Scientific and Industrial Research, New Delhi. 2001;5:176.

19. Vogel Al. Column and thin layer chromatography. In: Mendham, J., Denney, R.C., (eds) Text book of quantitative chemical analysis, 6th edn. Harlow, England, Newyork, Prentice Hall, New Jersey. 2000;279-88.

20. Wagner H, Bladt S. Plant Drug Analysis: A Thin Layer Chromatography Atlas. $2^{\text {nd }}$ Edition, Springer-Verlag, Berlin. 1996

21. Harborne JB. Phytochemical methods: A guide to modern technique of plant analysis. Champman and Hall, London. 1998;182-190.

22. Simona IV, Cornelia P, Laura R, Laslo V. Separation of pigments from petunia's petals using thin layer chromatography. Analele Universitatii din Oradea, Fascicula: Protectia Mediului. 2008;13:229-33.

23. Stanl E. Thin layer chromatography. Springer verlog, Berlin, Heidelberg, Newyork. 1997;3:694

24. Andrews JM. Determination of minimum inhibitory concentrations. J Antimicrob Chemother. 2001;48(1):5-16.

25. Mahesh B. Satish S. Antimicrobial activity of some important medicinal plant against plant and human pathogens. World J Agric Sci. 2008;4(S):839-43.

26. Jeyadevi R, Sivasudha T, Ilavarasi A, Thajuddin N. Chemical Constituents and Antimicrobial Activity of Indian Green Leafy Vegetable Cardiospermum halicacabum. Ind J Microbio. 2013;53(2):208-13

27. Abirami P, Rajendran A. GC-MS determination of bioactive compounds of Indigofera aspalathoides. J Nat Prod Plant Res. 2011;1(4):126-30.
28. Jayanta KP, Hrudayanath T. Anticancer activity and chromatography characterization of methanol extract of Heritiera fomes Buch. Ham, a mangrove plant from Bhitarkanika, India. Oriental Pharm. Experimen Med. 2013;13(2):133-42.

29. Silverstein RM, Webster FX, Kiemle DJ. Proton NMR spectrometry. Spectrometric identification of organic compounds, $7^{\text {th }}$ edn. John Wiley and Sons, Inc USA. 2005;127-204.

30. Mohan VR, Chenthurpandy P, Kalidass C. Pharmacognostic and phytochemical investigation of Elephantopus scaber L. (Asteraceae). J Pharmaceu SciTechnol. 2010;2(3):191-7.

31. Xu HX, Lee SF. Activity of plant flavonoids against antibiotic-resistant bacteria. Phytother Res. 2001;15(1):39-43.

32. Tsuchiya $H$, Sato $M$, linuma M, Yokoyama J, Ohyama M, Tanaka T, Takase I, et al. Inhibition of the growth of cariogenic bacteria in vitro by plant flavanones. Experientia. 1994;50(9):846-9.

33. Stefanovic O, Radojevic I, Comic L, Vasic S. Antibacterial activity of naturally occurring compounds from selected plants. Antimicrobial Agents InTech Rijeka Croatia. 2012.

34. Cowan MM. Plant products as antimicrobial agents. Clin Microbiol Rev. 1999;12(4):564-82.

35. Wu T, He M, Zang X. A structure-activity relationship study of flavonoids as inhibitors of $E$. coli by membrane interaction effect. Biochimica et Biophysica Acta (BBA)—Biomem. 2013;1828(11):2751-6.

36. Alcaraz LE, Blanco SE, Puig ON, Tomas F, Ferretti FH. Antibacterial activity of flavonoids against methicillin-resistant Staphylococcus aureus strains. JTheore Bio. 2000;205(2):231-40.

37. Lim SH, Darah I, Jain K. Antimicrobial activities of tannins extracted from Rhizophora apiculata barks. J Trop Forest Sci. 2006;18(1):59-65.

38. Mandal P, Sinha BSP, Mandal NC. Antimicrobial activity of Saponins from Acacia auriculiformis. Fitoterapia. 2005;76(5):462-565.

39. Manjunatha BK. Antibacterial activity of Pterocarpus santalinus. Ind J Pharmaceu Sci. 2006;68(1):115-6.

40. Hossain MA, Shah MD, Sakari M. Gas chromatography-mass spectrometry analysis of various organic extracts of Merremia borneensis from Sabah. Asi Pac J Trop Med. 2011;4(8):637-41.

41. Dobre AA, Gagiu V, Petru N. Antimicrobial activity of essential oils against foodborne bacteria evaluated by two preliminary methods. Romanian Biotechnol Lett. 2011;16(6):119-25.

42. Jeyadevi R, Sivasudha T, Rameshkumar A, Dineshkumar L. Anti-arthritic activity of the Indian leafy vegetable Cardiospermum halicacabum in Wistar rats and UPLC-QTOF-MS/MS identification of the putative active phenolic components. Inflamm Res. 2012. doi:10.1007/s00011-012-0558-z.

43. Aseer M, Akbar I. Potential in vitro antimicrobial efficacy of Holigarna arnottiana (Hook F). Asi Pac J Trop Biomed. 2014;4(1):25-9.

44. Ruchi SSK, Maharia RS, Garg AN. Identification of new phytoconstituents and antimicrobial activity in stem bark of Mangifera indica (L.). J Pharmac Biomed Anal. 2015;105:150-5.

45. Barbosa FVM, Waczuk EP, Kamdem JP, Abolaji AO, Lacerda SR, Costa JGM Phytochemical constituents, antioxidant activity, cytotoxicity and osmotic fragility effects of Caju Anacardium microcarpum. Indus Crops and Prod. 2014;55: 280-288.

46. Raju G, Subash N, Maridass M. HPLC analysis of Phenolic compounds of Indigofera aspalathoides D.C. Botanical report. 2013;2(2):1-6.

47. Kumar S, Pandey AK. Chemistry and biological activities of flavonoids: an overview Sci W J. 2013;1-16.

48. Gopalakrishnan VK, Starlin T, Arul RC, Ragavendhran P. Phytochemical screening functional groups and elemental analysis of Tylophora Pauciflora. Int Res J Pharm. 2012;3(6):180-3.

49. Griffiths PR, Haseth JAD. Fourier transform infrared spectroscopy. John wiley and Sons, New York, United States. 1986;708-9.

50. Havsteen B. Flavonoids, a class of natural products of high pharmacological potency. Biochem Pharmac. 1983;32(7):1141-8.

51. Kalaiselvi M, Gomathi D, Vidya B, Uma C. Evaluation of antioxidant potential and fourier transform infrared spectroscopy analysis of Annona squamosa. Int Res J Pharm. 2012:3:237-42

52. Durga MLN, Mahitha B, MadhaviT, John SN. Phytochemical Screening and FTIR Analysis of Clitoria ternatea leaves. Int J Scient Engin Res. 2015;6(2):287-90.

53. Saraf A. Phytochemical and antimicrobial studies of medicinal plant Costus speciosus (Koen.). E-J Chem. 2010;7(1):405-13.

54. Patra JK, Gouda S, Sahoo SK, Thatoi HN. Chromatography separation, $1 \mathrm{H}$ NMR analysis and bioautography screening of methanol extract of Excoecaria agallocha L. from Bhitarkanika, Orissa, India. Asi Pac J Trop Biomed. 2012;2(1) S50-S56.

Cite this article: Kumar TT, Salique SM, Ilyas MHM, Thajuddin N, Panneerselvam A, Padusha MSA, Jahangir HS. Phytochemical Screening and Antimicrobial Studies in Leaf Extracts of Indigofera aspalathoides (Vahl.). Pharmacog J. 2018;10(6):1208-15. 
GRAPHICAL ABSTRACT

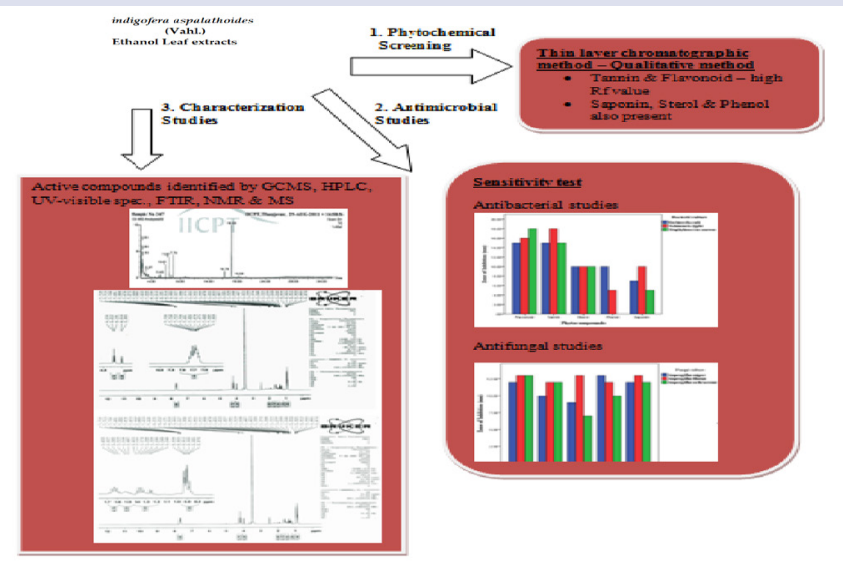

\section{SUMMARY}

- In this study, various phytochemical compounds were isolated from the ethanolic leaf extract of Indigofera aspalathoides (Vahl.)

- Antimicrobial studies were performed for the isolated compounds.

- GC-MS were performed for the identification of the compounds

- HPLC, FTIR and NMR analysis were performed for the isolation and characterization of compounds

- This plant extract contains bioactive compound, effectively worked against obligate pathogens

\section{ABOUT AUTHORS}

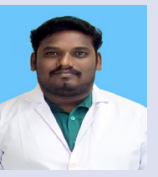

Tamilarasan Tamil Kumar, completed his Post graduate in the year 2009 and Master of Philosophy in 2012 in the Department of Botany, Jamal Mohamed College (Autonomous), Tiruchirappalli, Tamil Nadu (India). He started his research in the year 2012 in the same institution especially as specialization in Environmental Microbiology and Bioremediation. 